\title{
Approach to patients with pseudo-Cushing's states
}

\author{
Carla Scaroni ${ }^{1}$, Nora M Albiger ${ }^{1}$, Serena Palmieri ${ }^{2}$, Davide lacuaniello ${ }^{3}$, Chiara Graziadio ${ }^{4}$, Luca Damiani ${ }^{5}$, \\ Marialuisa Zilio ${ }^{1}$, Antonio Stigliano ${ }^{6}$, Annamaria $\mathrm{Colao}^{3}$ and Rosario Pivonello ${ }^{3}$ on behalf of the Altogether to Beat \\ Cushing's Syndrome (ABC) study group
}

\author{
1Dipartimento di Medicina, U.O.C. Endocrinologia, Università di Padova, Padova, Italy \\ 2Department of Clinical Sciences and Community Health, University of Milan, Fondazione IRCCS Cà Granda-Ospedale Maggiore Policlinico, Milan, Italy \\ ${ }^{3}$ Dipartimento di Medicina Clinica e Chirurgia, Sezione di Endocrinologia, Università Federico II di Napoli, Napoli, Italy \\ ${ }^{4}$ Department of Experimental Medicine, University La Sapienza, Rome, Italy \\ ${ }^{5}$ Department of Medical Sciences, Endocrinology and Internal Medicine Section, University of Ferrara, Ferrara, Italy \\ ${ }^{6}$ Department of Clinical and Molecular Medicine, Sant'Andrea Hospital, University La Sapienza, Rome, Italy
}

Correspondence should be addressed to C Scaroni: carla.scaroni@unipd.it

\begin{abstract}
The distinction between pseudo-Cushing's states (PCS) and Cushing's syndrome (CS) poses a significant clinical challenge even for expert endocrinologists. A patient's clinical history can sometimes help to distinguish between them (as in the case of alcoholic

Key Words

- pseudo-Cushing's

- neuropsychiatric disorders

individuals), but the overlap in clinical and laboratory findings makes it difficult to arrive at $\downarrow$ PCOS

a definitive diagnosis. We aim to describe the most common situations that can give rise to a condition resembling overt endogenous hypercortisolism and try to answer questions that physicians often face in clinical practice. It is important to know the relative prevalence of these different situations, bearing in mind that most of the conditions generating PCS are relatively common (such as metabolic syndrome and polycystic ovary syndrome), while CS is rare in the general population. Physicians should consider CS in the presence of additional features. Appropriate treatment of underlying conditions is essential as it can reverse the hormonal abnormalities associated with PCS. Close surveillance and a thorough assessment of a patient's hormone status will ultimately orient the diagnosis and treatment options over time.

- alcoholism

- diabetes

obesity

- eating disorders
\end{abstract}

\section{Introduction}

Physiological activation of the hypothalamicpituitary-adrenal (HPA) axis can be found in several situations, such as major surgery, severe illness, intensive physical exercise, and prolonged fasting leading to improve the ability of the organism to survival (1).

Some common endocrine diseases including obesity, polycystic ovary syndrome (PCOS), poorly controlled diabetes mellitus (DM), chronic alcoholism, and psychiatric disorders may also coincide with HPA axis activation (2). Under such conditions, there may be some clinical signs of hypercortisolism, which may be temporary or more persistent, giving rise to what is called pseudo-Cushing's syndrome (PCS).

The differential diagnosis of PCS and Cushing's syndrome (CS) is still a major clinical challenge even for expert endocrinologists. Study findings are inconsistent and no consensus on the correct diagnosis has been reached as yet. Standard adrenal steroid measurements often overlap in cases of PCS and CS, and several drugs affect the dynamic test results.

By describing and discussing a clinical case, this review attempts to answer some common questions that physicians may face in the clinical practice.

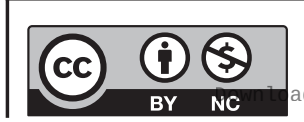




\section{Clinical case}

A 26-year-old female was referred to a tertiary endocrine center for suspected endogenous hypercortisolism. She had a long-standing diagnosis of type- $1 \mathrm{DM}$ and a psychiatric condition characterized by depression and anxiety that was treated with fluoxetine.

She had experienced oligomenorrhea since her first menstrual cycle at 14 years of age. At 20 years of age, she was diagnosed with polycystic ovarian syndrome (PCOS) based on her oligomenorrhea, hyperandrogenism, and micropolycystic ovaries found on pelvic ultrasound. She began taking oral estro-progestin therapy and was continuing to do so at the time of our assessment. During a hospitalization for a suspected bowel obstruction, she had revealed some clinical signs suggestive of hypercortisolism (central adipose distribution, hirsutism, and round face, but no evidence of proximal myopathy or reddish purple striae). She was overweight (BMI $28 \mathrm{~kg} / \mathrm{m}^{2}$, with a waist circumference of $92 \mathrm{~cm}$ ), with high blood pressure (140/90 $\mathrm{mmHg})$.

Laboratory findings revealed high levels of serum cortisol at 08:00 h (29 $\mu \mathrm{g} / \mathrm{dL} ;$ n.v. 5-25), and high urinary free cortisol (UFC) $(280 \mu \mathrm{g} / 24 \mathrm{~h}$; n.v. 36-137), while ACTH levels at 08:00 $\mathrm{h}$ were in the normal range $(26 \mathrm{pg} / \mathrm{mL}$; n.v. 10-50). The patient's diabetes was poorly controlled (HbA1c 8\%).

The suspected CS was confirmed by the lack of cortisol suppression after $1 \mathrm{mg}$ dexamethasone $(10 \mu \mathrm{g} / \mathrm{dL}$, n.v. <1.8) and the absence of a cortisol circadian rhythm (midnight serum cortisol, MserC, $12 \mu \mathrm{g} / \mathrm{dL}$; n.v. <7.5).

\section{Which clinical features are the strongest indicators of CS?}

Easy bruising, facial plethora, proximal myopathy, and cutaneous striae (reddish purple $1 \mathrm{~cm}$ wide) are reportedly the clinical features that best discriminate CS (3). These signs were all lacking in our patient, but we knew that most of these features have a low sensitivity. The patient had a round face and was overweight, with central adipose distribution and hirsutism, features that are commonly seen in CS patients, but of lower discriminatory value. On the other hand, these signs are indistinguishable from patients with PCOS, which is a common disease among women of reproductive age (4), whereas CS is more rare (5).

\section{Which is the first-line approach for patients with suspected CS?}

The Endocrine Society guidelines recommend using the $1 \mathrm{mg}$ dexamethasone suppression test (1-mg DST), latenight salivary cortisol (LNSC; two measurements), or UFC (two measurements) for first-line screening purposes. Then, additional methods such as a longer, low-dose DST ( $2 \mathrm{mg}$ for $48 \mathrm{~h}$ ) and midnight serum cortisol, may be considered $(3,6)$.

LNSC is increasingly used nowadays (7), based on the assumption that most patients with CS lose their normal cortisol diurnal pattern and have persistently elevated cortisol levels throughout the day, whereas PCS patients retain their normal secretion rhythm, albeit on a higher setting, with a cortisol nadir at midnight (8). Although further studies are needed to confirm these findings, LNSC seems to perform better than 1-mg DST or UFC in distinguishing PCS from CS. Unlike the midnight serum cortisol measurement that requires inpatient admission, saliva collection is easy to perform in an outpatient setting. However, LNSC is not widely used in the clinical practice and the studies reported have not set a clearly defined cut-off value to be used in the diagnosis of CS. Thus, each center should determine its own cut-off value based on the method adopted for LNSC measurement.

UFC provides an integrated assessment of cortisol secretion over a $24-\mathrm{h}$ period. It measures the cortisol that is not bound to corticosteroid-binding globulin (CBG), which is filtered by the kidney unchanged. A falsely low UFC can occur when creatinine clearance falls less than $60 \mathrm{~mL} / \mathrm{min}$ (3). It is important that patients provide complete urine collections with appropriate total volumes (this may require an adequate patient education) and the concomitant measurement of urinary creatinine levels.

\section{Which aspects should be considered before screening patients with suspected CS?}

When performing cortisol assays, it is important to consider analytical bias. There are two ways to measure cortisol: immunoassays, for example, RIA, ELISA, or automated chemiluminescence (ECLIA) and liquid chromatography-tandem massspectrometry (LC-MS/MS). Antibody-based immunoassays can be affected by crossreactivity (especially cortisone, which has a structure similar to that of cortisol) and synthetic glucocorticoids (9). In fact, cortisol is converted into inactive cortisone by $11 \beta$-hydroxysteroid dehydrogenase (11ß-HSD) type 2 .

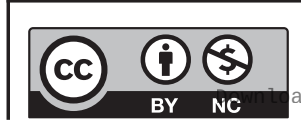

This work is licensed under a Creative Commons Attribution-NonCommercial 4.0 International License. ded from Bioscientifica.com at 04/26/2023 06:56:14AM via free access 
Structure-based assays like LC-MS/MS do not pose this problem and allow for various glucocorticoids and metabolites to be separated, and they are probably the most accurate methods for assessing cortisol and cortisone levels (9).

The concomitant use of commonly prescribed therapies may alter dexamethasone metabolism, interfering with its use in a suppression test. Some types of medication can interfere with the CYP3A4 enzyme system, either accelerating (i.e. phenobarbital, phenytoin, carbamazepine, pioglitazone, primidone, rifampin, rifapentine, and ethosuximide) or impairing (i.e. aprepitant, itraconazole, ritonavir, fluoxetine, diltiazem, and cimetidine) dexamethasone metabolism (3).

Measuring dexamethasone levels could help to identify any abnormal clearance. A recent study has used a rapid and sensitive LC-MS/MS assay for measuring dexamethasone levels in a cohort of normal healthy postmenopausal women. Applying a serum dexamethasone cut-off of $>3.3 \mathrm{nmol} / \mathrm{L}$ was associated with a serum cortisol $\leq 50 \mathrm{nmol} / \mathrm{L}$ in $84 / 95$ of the individuals (10). However, serum dexamethasone levels are not measured routinely in international clinical practice.

Oral estrogens can increase CBG levels and consequently raise total cortisol levels, again potentially generating abnormal test results $(11,12,13)$.
Oral estrogens should be withdrawn for at least 6 weeks before testing or retesting patients with suspected CS (3).

Our patient was taking fluoxetine, which inhibit the CYP3A4 system leading to impaired dexamethasone metabolism, and oral estrogens that can influence the result of any test.

\section{How can patients' concomitant conditions influence the diagnosis of PCS?}

\section{Neuropsychiatric disorders}

HPA axis hyperactivity is a frequent finding in patients with major depressive disorder (MDD) (14). Overall, about $20-30 \%$ of patients with MDD reveal hypercortisolemia $(15,16)$. Depressed male patients appear to have a more reliable cortisol hypersecretion, raising the issue of sex differences in HPA axis hyperactivity in depressed patients $(16,17)$ (Table 1).

The post-awakening surge in cortisol is known to be accentuated in individuals at risk of MDD (18), and about one in two patients with MDD have high evening cortisol levels indicative of disrupted diurnal cortisol rhythms $(14,19)$. The defect that induces HPA axis overactivity seems to be localized in the upper part of the hypothalamus, and there have been reports of increased levels of

Table 1 Most common causes of PCS and main associated abnormalities of the hypothalamus-pituitary adrenal-axis (HPA) reported.

Causes of PCS

Neuropsychiatric disorders

Obesity

Alcohol abuse

Eating disorders

\section{Abnormalities of HPA axis reported}

Accentuated post-awakening surge in cortisol

High evening cortisol levels in some patients

Increased or decreased $\mathrm{CRH}$ levels

Resistance to the feedback action of DST on HPA axis activity

Reduced activity of cortisol-deactivating enzymes (5- $\alpha$-reductase and $11 \beta$-HSD type 2 )

Mildly elevated UFC levels in $~ 50 \%$ of patients

Decreased corticosteroid-binding globulin

Increased androstenedione, total and free testosterone levels

Reduced sex hormone-binding globulin

Increased cortisol reactivity to physical and psychosocial stressors

Preserved pituitary sensitivity to feedback inhibition by DST

Increased $5 \alpha$-reductase type 1 activity in the liver

Upregulation of cortisol output due to great expression of $11 \beta$-HSD type 1

Stimulated $\mathrm{CRH}$ production with increased ACTH levels

Higher fasting cortisol at $08.30 \mathrm{~h}$

Impaired cortisol clearance due to hepatic dysfunction

Abnormal cortisol suppression to 1-mg DST

Reduced cortisol clearance

Changes in the affinity of cortisol to CBG

Resistance to the action of glucocorticoids

High CRH levels with normal ACTH

Preserved circadian rhythm of cortisol https://ec.bioscientifica.com

https://doi.org/10.1530/EC-19-0435 (c) 2020 The authors Published by Bioscientifica Ltd

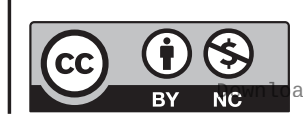

This work is licensed under a Creative Commons Attribution-NonCommercial 4.0 International License. ded from Bioscientifica.com at 04/26/2023 06:56:14AM 
corticotropin-releasing hormone (CRH) in depression, as well as a significant decrease in this hormone in atypical depression (20).

A proportion of patients with MDD also have a greater resistance to the feedback action of glucocorticoids on HPA axis activity $(20,21)$ and this weaker sensitivity is often restored by effective psychopharmacological therapy (22).

Data regarding the pulsatile release of cortisol and ACTH in depressed patients are ambiguous, with reports of increased (23), unchanged (24), or reduced (25) frequencies. Analyzing these conflicting findings of different studies suggests that the prevalence of abnormalities in cortisol and ACTH levels might depend partly on how they are measured and the type of depressed patients examined. Many such patients nonetheless reveal one or more abnormal test among an abnormal cortisol suppression with the 1-mg DST or higher night-time and urinary cortisol levels.

A reduced activity of the intracellular cortisoldeactivating enzymes (5- $\alpha$-reductase and $11 \beta$-HSD type 2) has been demonstrated in depressed patients too, and this may raise the cortisol bio-availability within tissues (25). Certain therapies for depression may improve

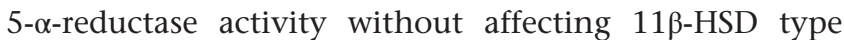
2 activity, and this would explain why the disrupted glucocorticoid metabolism may be only partly improved by antidepressants (25).

Finally, it has been claimed that cortisol dysfunction in patients with MDD could be one of the factors involved in their higher risk of metabolic syndrome and type $2 \mathrm{DM}$ (26) and their higher cardiovascular mortality $(27,28)$.

\section{Polycystic ovary syndrome (PCOS)}

Anovulation, oligo-amenorrhea, hirsutism, acne, insulin resistance, DM, overweight/obesity, and hypertension may be seen to a variable degree in PCOS and CS patients. There is a difference in their prevalence, however, PCOS is quite common, occurring in $6.6 \%$ of women of reproductive age (4), whereas CS is a rare condition with an incidence of $0.7-2.6$ cases per million population yearly (5). The two conditions may overlap in some young women. In a retrospective review of patients of reproductive age with a confirmed diagnosis of CS, one in two were initially diagnosed with isolated PCOS (29). The patients had nearly identical clinical profiles, except that hirsutism and menstrual irregularities were more common in those initially diagnosed with PCOS. These findings are of interest because treatment for PCOS did not solve the hypercortisolism, and the oral estrogens generally used to treat PCOS may be deleterious in CS patients due to their high thrombotic risk. A delay in the diagnosis of CS can have important clinical consequences too.

On the other hand, a prospective study conducted on premenopausal women with proven CS found signs and symptoms of hyperandrogenism in all patients, menstrual irregularities in 70\%, and a polycystic ovarian morphology in $46 \%$ (30). This report confirms that a PCOS phenotype is common in CS women, particularly among those with moderately high glucocorticoid levels (31). When circulating cortisol exceeds critical levels, there is an inhibitory effect on the hypothalamic control of gonadotropin release and ovarian volumes seem to be preserved.

Pall et al. (32) hypothesized that total testosterone (TT) levels could be lower in patients with mild CS compared to women with PCOS. They found that the optimal cutoff for TT was $1.39 \mathrm{nmol} / \mathrm{L}$, yielding a sensitivity of $95 \%$ and a specificity of $70 \%$. The evaluation was done with a well-validated assay, but most commercial assays lack of accuracy and precision when measuring testosterone in women. Moreover, only subjects identified with mild CS of pituitary origin were included in the study and so the criteria cannot be applied to patients with other forms of CS. Thus, larger studies are needed to confirm these data.

It may be reasonable to screen women with PCOS for hypercortisolism. The 1-mg DST has a high specificity and diagnostic accuracy. The test maintained its sensitivity using a lower cut-off, and this is important in a screening setting (33). Measuring midnight plasma cortisol levels is a highly sensitive method too, while caution is needed in interpreting mildly elevated UFC levels in women with PCOS. In both, normal weight and obese patients with PCOS, UFC may exceed the upper limit of the normal range in about $50 \%$ of the patients (34).

\section{Diabetes mellitus, obesity and metabolic syndrome}

Although limited data are available on the prevalence of CS in patients with DM, the diagnosis should be considered particularly in cases with a number of highly discriminatory signs or symptoms.

After screening a large number of patients attending diabetes clinics in an outpatient setting and in conditions of standard clinical practice, Terzolo et al. (35) found a frequency of previously unsuspected CS of $0.7 \%$ (in the largest series published so far). Its frequency was higher (5.1\%) among patients whose diabetes and hypertension were poorly controlled despite intensive treatment. In a previous series, Catargi et al. (36) found a definitive CS in

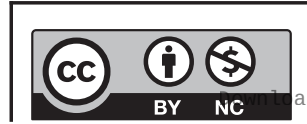

This work is licensed under a Creative Commons Attribution-NonCommercial 4.0 International License. ded from Bioscientifica.com at 04/26/2023 06:56:14AM 
$2 \%$ of overweight, type-2 DM patients referred for poor metabolic control. In both studies, a first screening was performed with the 1-mg DST.

Although these results do not support a widescale screening for CS in type-2 DM patients, a casefinding approach is warranted for selected patients with uncontrolled glycemia or resistant hypertension.

Obesity is an ongoing pandemic condition, the prevalence of which is continuing to rise worldwide.

The association between cortisol and obesity has been extensively studied and it appears that obesity is often, but not always, related to a hyperresponsive HPA axis (37). The studies indicate that cortisol secretion is often elevated but that circulatory concentrations are normal or low probably due to substantial changes in peripheral metabolism of cortisol (38). These changes are tissue specific, with increased inactivation of cortisol in the liver (by increased 5 $\alpha$-reductase type 1 activity that metabolizes cortisol to its tetrahydro derivatives) and increased regeneration of cortisol in adipose tissue (39). The increased inactivation of cortisol in the liver may be responsible for the compensatory activation of the HPA axis.

Women with abdominal obesity phenotype have an exaggerated ACTH and cortisol response to combined $\mathrm{CRH} / \mathrm{AVP}$ (corticotropin-releasing hormone/arginine vasopressin) stimulation (40). Higher than normal UFC values have been found in women with abdominal obesity $(41,42)$. However, these data were not confirmed when anxiety and depression were excluded (40), suggesting that confounding factors are capable of altering the HPA axis in obesity.

Increased cortisol reactivity observed after both, physical and psychosocial acute stressors, seems to be the one parameter where results are consistent in obese subjects $(40,41,43)$.

Subtle differences in pituitary feedback sensitivity have been found in the cortisol response to dexamethasone test. Abdominal obesity seems to be associated with poorer response using $0.5 \mathrm{mg}$ of dexamethasone overnight (43). However, Pasquali et al. (44) demonstrated that pituitary sensitivity to dexamethasone administration is preserved in obese subjects of both sexes even at low dosages.

Abraham et al. (45) analyzed the associations between three parameters of activity of the HPA axis (nadir of salivary cortisol levels, UFC, and the $1 \mathrm{mg}$ DST) and weight, metabolic syndrome and psychosocial stress in a large number of overweight and obese individuals with at least two features of CS. Apart from a weak correlation of salivary cortisol in men, they found no relationship between waist circumference and any cortisol parameter. Their findings do not support a strong link between systemic cortisol and obesity or metabolic syndrome.

Many of the inconsistencies found in the different studies may be associated to various cortisol measurements methodology and different study designs.

Particular attention has been posed to the activity of the $11 \beta$-HSD type 1 localized in different tissues. This is a microsomal enzyme which converts inactive cortisone to active cortisol, thus regulating intracellular cortisol access to glucocorticoid receptor. Although data are inconsistent, there is a suggestion that local glucocorticoids action may be amplified by upregulated activity of 11ß-HSD type 1 in visceral and hepatic tissue of obese subjects $(46,47)$. Omental fat can generate active cortisol from inactive cortisone via $11 \beta-H S D$ type 1 , amplify glucocorticoid receptor activation, and promote pre-adipocyte differentiation and adipocyte hypertrophy, inducing adiposity (46). The increased expression of $11 \beta$-HSD type 1 in omental adipose tissue seems to support its involvement in severe obesity (48).

However, a number of respective studies have been performed in animal models and in humans with controversial results (49) probably associated to the differentially expression and activity of 11/-HSD type 1 in different species and tissues.

Several inhibitors of 11- $\beta$ HSD type 1 have consequently been tested in animals, obtaining an improvement in glucose control and lipid profile $(47,50)$.

Even though being controversially discussed, the role of $11 \beta$-HSD type 1 in the pathogenesis of the metabolic syndrome must be further considered.

\section{Which other situations can be associated with PCS?}

\section{Alcohol abuse}

The first report on patients with symptoms mimicking CS caused by alcoholism appeared at the end of the 1970s (51). Studies conducted in mice demonstrated that alcohol can stimulate $\mathrm{CRH}$ production via the hypothalamic paraventricular nucleus, with consequent HPA axis activation and increased levels of ACTH (52). Induction of the enzyme 11- $\beta$ HSD type 1 was demonstrated in patients with alcoholic liver disease, coinciding with an increased cortisol production or an impaired cortisol clearance due to hepatic dysfunction. 
Although the severe classical phenotype is not difficult to diagnose, chronic alcoholism can induce a phenotype that largely overlaps with CS. Several case reports have provided details emerging from the physical examination of patients with symptoms compatible with CS, which eventually proved to be the result of alcohol addiction: $87 \%$ had a moon face, $81 \%$ had muscle weakness or tiredness, $75 \%$ had truncal obesity, $69 \%$ had hypertension, and $12 \%$ had cutaneous striae (53).

Coiro et al. (54) measured cortisol in ten women with alcohol-induced PCS and found a higher fasting cortisol at $08.30 \mathrm{~h}$ than in controls. Frias et al. (55) examined adolescents during episodes of acute alcohol intoxication, finding elevated cortisol levels, which was more pronounced in females. Studying the presence of cortisol in the hair, Stalder et al. (56) detected higher levels in individuals who had recently stopped drinking alcohol than in either controls or individuals who had abstained for a longer period. When heavy drinkers were compared with light drinkers, the former had higher salivary cortisol levels on awakening and $30 \mathrm{~min}$ afterwards (57). An insufficient cortisol suppression in the 1-mg DST was also reported in several studies (53).

Interestingly, case reports invariably indicated that alcohol withdrawal led to the disappearance of patients' symptoms and biochemical disruptions (58).

A detailed clinical history is crucially important in patients with CS, and alcoholic patients should undergo a repeat of their clinical and biochemical work-up after they have stopped drinking alcohol for at least 1 month (53).

\section{Eating disorders}

Anorexia nervosa is a psychiatric disorder characterized by an extreme restriction of food intake despite being underweight, with a refusal to maintain body weight above the minimum threshold of normality. It can severely alter the patient's eating behavior and is associated with mortality rates of up to $22 \%$. Patients, usually women, have endocrine abnormalities such as amenorrhea, an impaired body temperature regulation, and hypercortisolism, probably linked to chronic fastingrelated stress. HPA axis dysregulation may persist even after weight recovery, however, suggesting that it may be involved in the pathogenesis of the disease itself (59).

Hypercortisolism has been amply documented in young women with anorexia nervosa. Many mechanisms have been hypothesized, including a reduced cortisol clearance, changes in the affinity of cortisol for CBG, or in the concentration of glucocorticoid receptor. In particular, resistance to the action of glucocorticoids may explain not only the hypercortisolism but also the lack of clinical signs of cortisol excess in such underweight women.

The mechanisms behind hypercortisolism in anorexia nervosa appear to differ from those associated with MDD, with CRH having a more important role in stimulating the HPA axis in the case of anorexia. The powerful anorectic effect of CRH could contribute to the severe weight loss observed in this disorder (60): the levels of CRH are higher than normal, while those of ACTH are normal, and the latter has a reduced response to stimulation with $\mathrm{CRH}$, whereas adrenal cortisol production increases after stimulation with ACTH. Despite the changes in the HPA axis, the circadian rhythm of cortisol generally seems to be preserved in anorexia patients, although conflicting data emerged from some studies (61).

The functional cortisol excess seen in anorexia and bulimia can have numerous negative effects. Some data point to its role in promoting the psychological and cognitive changes observed in patients with anorexia. A relationship has also emerged between the lack of cortisol response to 1-mg DST suppression and the presence and severity of depressive symptoms associated with eating disorders.

Some authors have also underscored the possible role of cortisol in the onset of attention deficit, especially in anorexia. Nutritional deficiencies and hypercortisolism may also promote bone loss in such patients, and the influence of hypercortisolism on other pituitary axes (the gonadotropic, growth hormone, and thyroid) may be responsible for oligomenorrhea-amenorrhea and a reduced TSH secretion despite low levels of T3 and T4. Finally, although the hypercortisolism associated with anorexia nervosa may not lead to a build-up of fat tissue due to the lack of substrates, it can affect the disproportionate accumulation of central adiposity after recovery from illness.

\section{Getting back to our patient}

As regards her diagnosis, our patient had several conditions (a neuropsychiatric disorder, overweight, and PCOS) that can be associated with PCS, and most of them could be secondary to a genuine endogenous hypercortisolism. Another aspect to emphasize concerns the treatments she was taking (oral contraceptives and antidepressants) that may have interfered with her hormone assessment (i.e. serum cortisol midnight and in the 1-mg DST). When she was retested again after discontinuing these drugs, 
she still had mildly increased UFC levels (170 $\mu \mathrm{g} / 24 \mathrm{~h}$; n.v. 36-137), with normal serum cortisol levels 2 days after a 2-mg DST (1.2 $\mu \mathrm{g} / \mathrm{L}$ (n.v. <1.8)). LNSC was measured twice using the RIA method, producing different results $(2.0$ and $3.6 \mathrm{nmol} / \mathrm{L}$ n.v. 0.5-2.6).

With these results, mild CS still could not be ruled out.

\section{What more can be done to exclude or confirm CS?}

Second-line tests

\section{Midnight serum cortisol (MserC)}

A single MserC measurement using a cut-off of $207 \mathrm{nmol} / \mathrm{L}$ (7.5 $\mu \mathrm{g} / \mathrm{dL}$ ) was reportedly able to discriminate CS from PCS with a $96 \%$ sensitivity and $100 \%$ specificity (62). This was confirmed in further studies $(63,64)$ using higher cut-offs of $242 \mathrm{nmol} / \mathrm{L} ; 8.8 \mu \mathrm{g} / \mathrm{dL}$ in wakeful patients (51) and $<256 \mathrm{nmol} / \mathrm{L}(9.3 \mu \mathrm{g} / \mathrm{dL})$ in all patients with PCS (65). In one study (63), a midnight:morning cortisol ratio of 0.67 also seemed to discriminate well between cases of CS and PCS (Table 2), but this test involves hospitalizing the patient and may produce false-negative results in patients with mild or quiescent CS.

\section{Dexamethasone-suppressed corticotropin-releasing hormone stimulation test (Dex-CRH)}

This combined test involves 2 days of dexamethasone suppression followed by $\mathrm{CRH}$ stimulation. It was first introduced in 1993, based on the observation that patients with PCS are thought to have a decreased ACTH response to exogenous CRH stimulation, while the ability to suppress cortisol after exogenous administration of dexamethasone persists (65). This test has shown a variable performance in different studies, however. The first study reported an excellent discrimination between CS and PCS patients when serum cortisol concentrations measured 15 min after administering $\mathrm{CRH}$ were higher than $38 \mathrm{nmol} / \mathrm{L}(1.4 \mu \mathrm{g} / \mathrm{dL})(65)$. But these findings were not confirmed in later studies $(64,66)$ in which the test's weaker diagnostic performance led to the proposal of new cutoffs for cortisol 15 min after administering CRH. When plasma ACTH was analyzed in the same population, the best diagnostic performance was obtained with an ACTH concentration higher than $3.5 \mathrm{pmol} / \mathrm{L}(16 \mathrm{pg} / \mathrm{mL})$ 15 min after administering CRH (64). Different thresholds for ACTH and cortisol response proposed in other studies reportedly achieved different sensitivity and specificity levels (67) (Table 2).

Differences in the reliability of the Dex-CRH test emerging from the above-mentioned studies may be due to the use of different test protocols, ovine as opposed to human CRH preparations, doses of $1 \mu \mathrm{g} / \mathrm{kg}$ or $100 \mu \mathrm{g}$, different cortisol and ACTH assays (especially as regards measurements in the low range), and patients' characteristics (degree of hypercortisolism, adrenal vs pituitary CS).

\section{Low-dose dexamethasone suppression test (LDDST)}

This test which involved 2 days of dexamethasone suppression was found to perform reasonably well. In two previous studies, the diagnostic accuracy of the Dex-CRH test did not differ significantly from that of the standard LDDST when cortisol cut-offs of $50 \mathrm{nmol} / \mathrm{L}(1.8 \mu \mathrm{g} / \mathrm{dL})$ (66) or $55 \mathrm{nmol} / \mathrm{L}(2.0 \mu \mathrm{g} / \mathrm{dL})$ (64) were used, though another study did not confirm as much (63).

\section{CRH stimulation test}

This test is generally used to differentiate between ACTHdependent CS forms (68). Its low diagnostic accuracy when used alone to discriminate between patients with Cushing's disease (CD) and those with PCS has prevented its use for this purpose. Arnaldi et al. (69) recently examined whether applying novel criteria would enable the test to distinguish CD from PCS and from controls (CT). The authors suggested two separate combinations of parameters, each capable of diagnosing CD: (i.) basal serum cortisol $>331 \mathrm{nmol} / \mathrm{L}(12 \mu \mathrm{g} / \mathrm{dL})$ and peak plasma ACTH $>12 \mathrm{pmol} / \mathrm{L}(54 \mathrm{pg} / \mathrm{mL}$ ) or (ii.) peak serum cortisol $>580 \mathrm{nmol} / \mathrm{L}(21 \mu \mathrm{g} / \mathrm{dL})$ and peak plasma ACTH >10 $\mathrm{pmol} / \mathrm{L}(45 \mathrm{pg} / \mathrm{mL})$. These combinations yielded a greater diagnostic accuracy.

\section{Desmopressin stimulation test (DDAVP)}

DDAVP usually elicits a marked rise in plasma ACTH and serum cortisol in most CD patients, but not in cases of PCS or healthy individuals $(70,71)$.

It was previously claimed that a rise in plasma ACTH of at least $6 \mathrm{pmol} / \mathrm{L}$ within $30 \mathrm{~min}$ after DDAVP injection $(\Delta-\mathrm{ACTH})$ was the most effective diagnostic criterion for distinguishing CD from PCS patients (70).

Rollin et al. (72) found that a peak ACTH concentration of $15.8 \mathrm{pmol} / \mathrm{L}$ or an absolute increment of ACTH of 8.1 pmol/L over baseline could be used to correctly diagnose 93 or $92 \%$ of the patients, respectively.
This work is licensed under a Creative Commons Attribution-NonCommercial 4.0 International License. ed from Bioscientifica.com at 04/26/2023 06:56:14AM via free access 

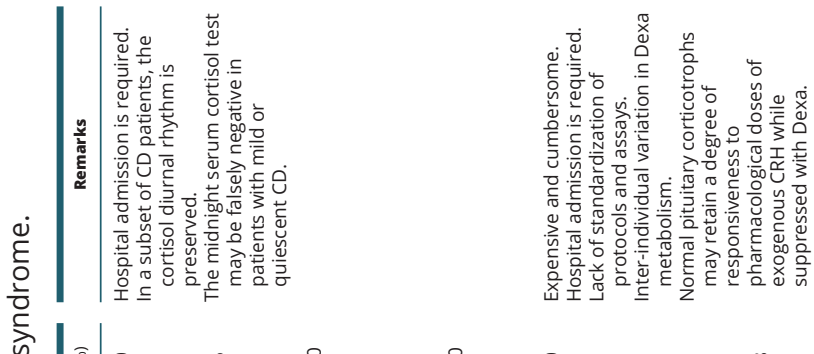

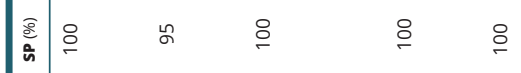
$\infty$
$\infty \bowtie$
ริ่
$\stackrel{8}{0}$
นู้

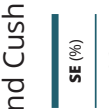
\& $\stackrel{\circ}{\circ} \stackrel{\circ}{\circ}$
$\stackrel{\circ}{\circ}$
웅
ㅇํำ
\&
$\stackrel{8}{1}$

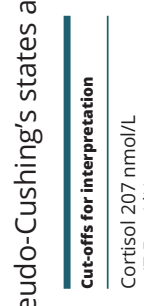

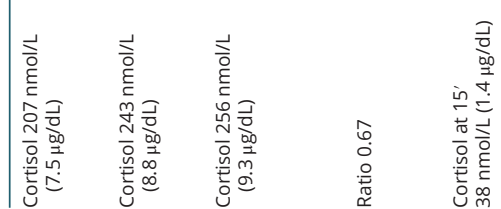

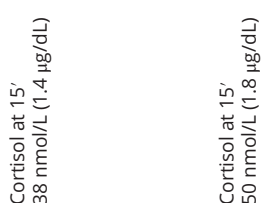

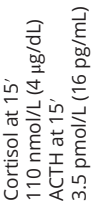

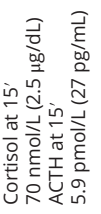

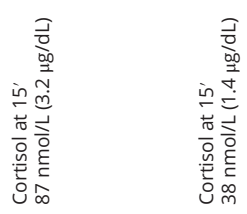

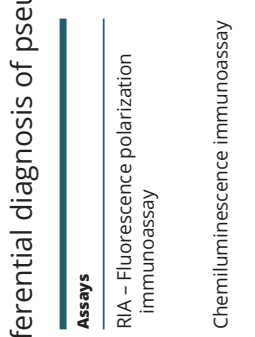

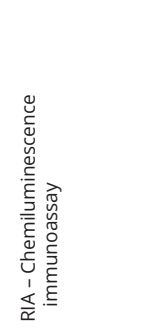

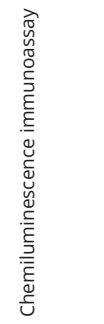
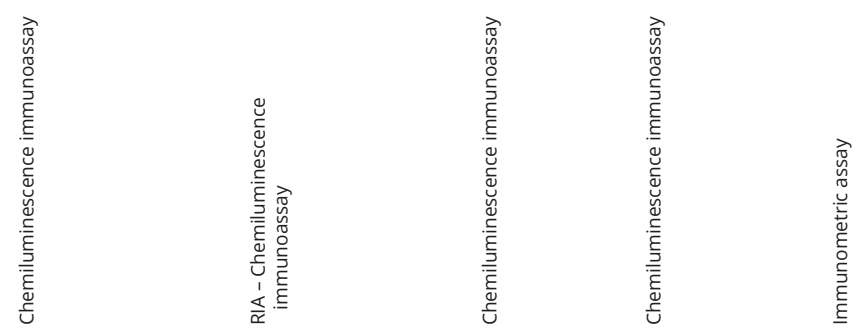

\section{궁ำ}

的产 든

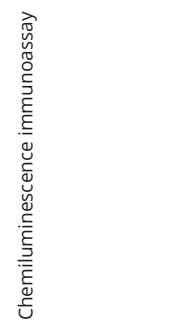

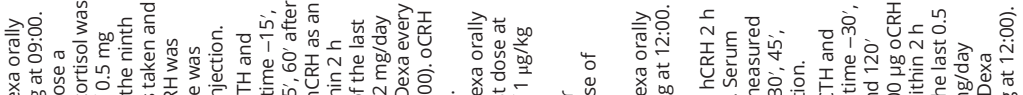

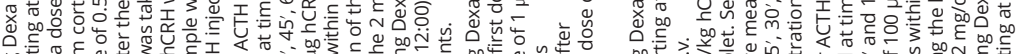

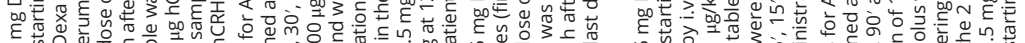

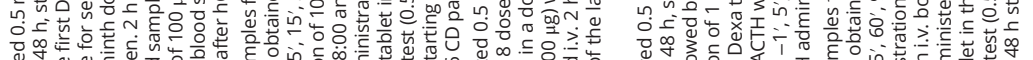

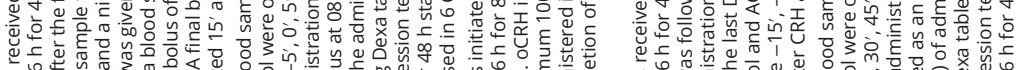

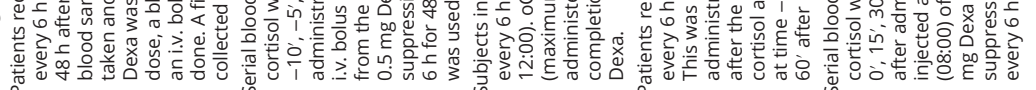
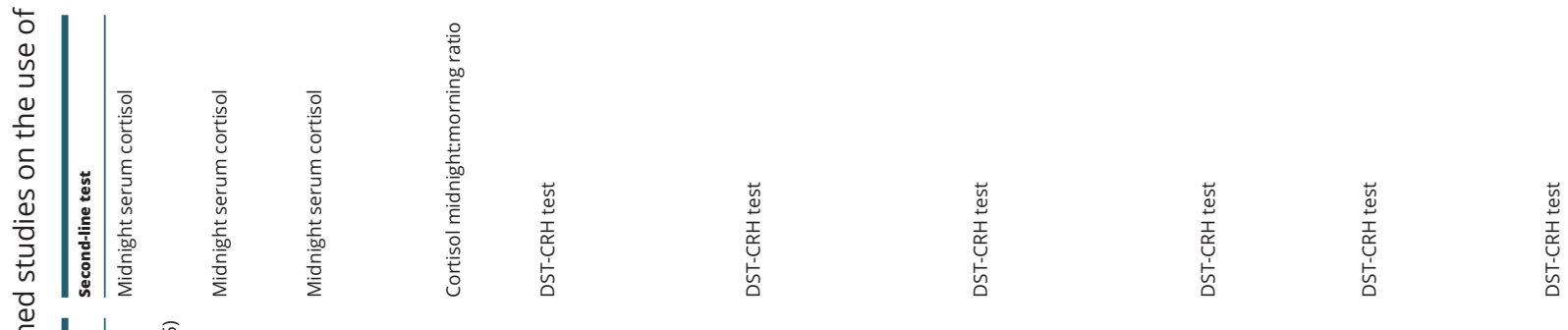

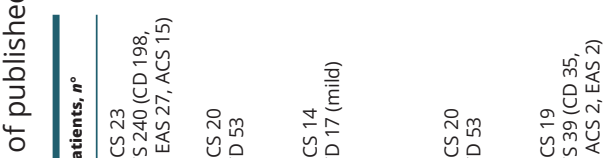

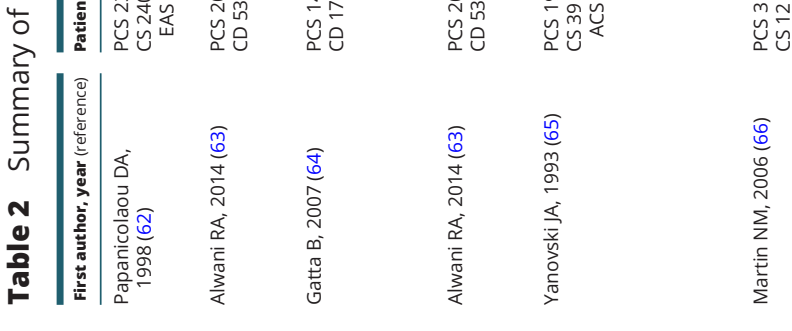

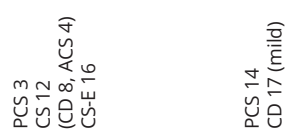

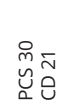

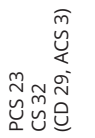
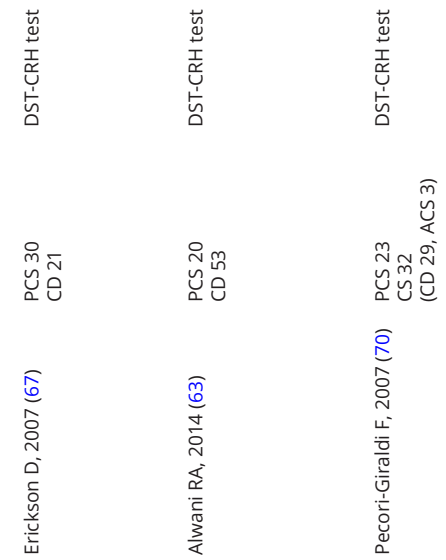


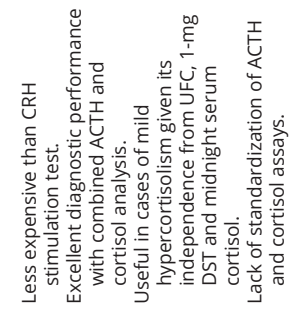

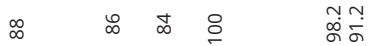

$\stackrel{\substack{m \\ \infty}}{\infty}$

กิ่

ㅇ

守灾

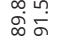

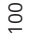

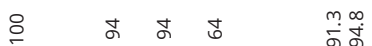

ஜூ요

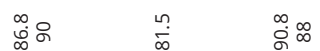

ํํํ.
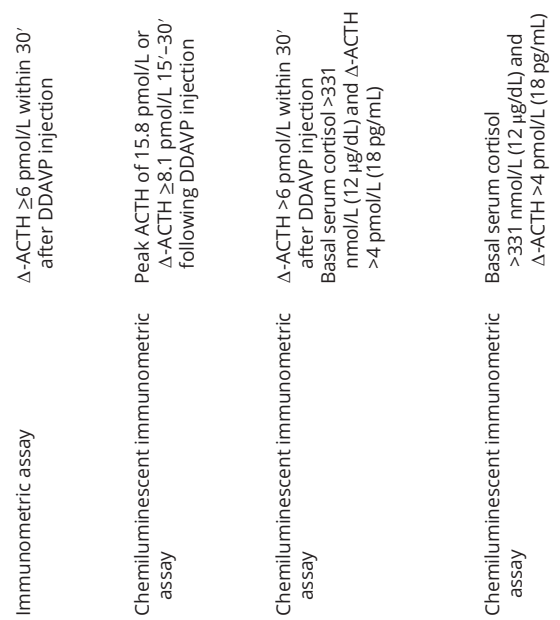

\section{$\frac{5}{\infty}$}

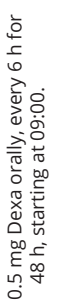
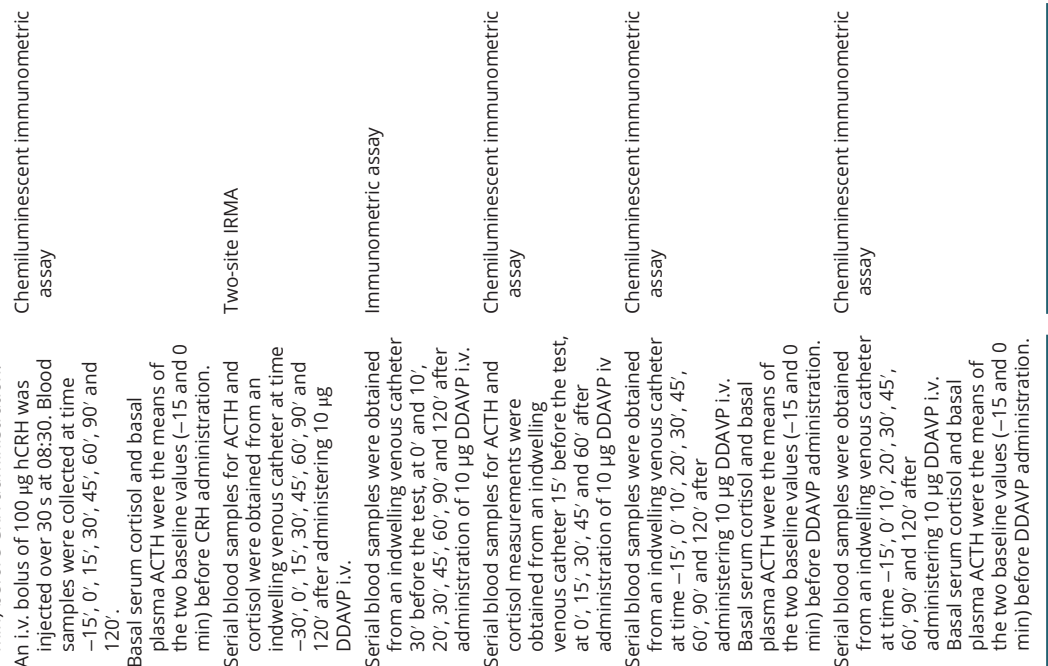

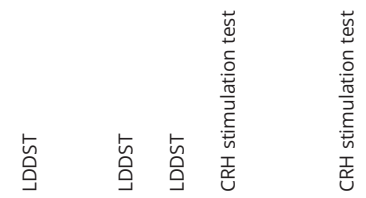

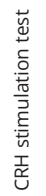

產

紊哭

裵

㢈

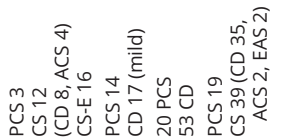

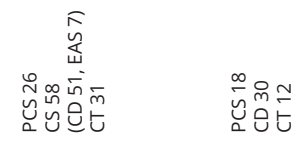

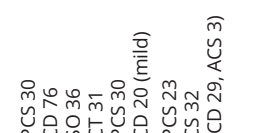

象

บึกินต

บูำำ

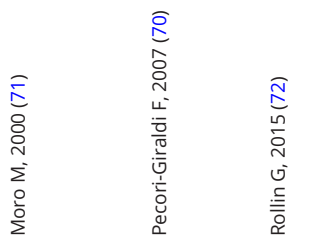

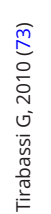

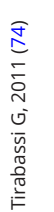

This work is licensed under a Creative Commons Attribution-NonCommercial 4.0 International License.

(c) 2020 The authors Published by Bioscientifica Ltd

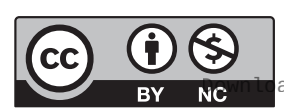

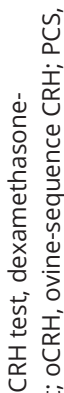

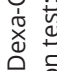

ฮ่̀

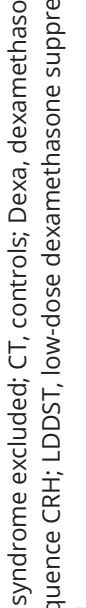

แิ

西

U

Uे

\section{(2) \\ 要

| \\ .}

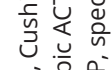
ज信 i 䆗这 离这岕

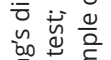

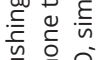

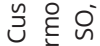
Qि $\frac{0}{0.0}$

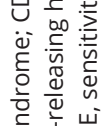
斑旁出 bo

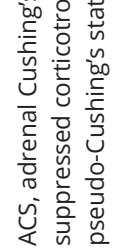


To improve the diagnostic performance of the DDAVP test, Tirabassi et al. (73) proposed a new combination of parameters consisting of simultaneous basal serum cortisol and $\triangle$-ACTH levels: they found that a diagnosis of $\mathrm{CD}$ could be excluded for patients who were positive for one or neither of these parameters.

\section{Combined assessment of second-line tests}

Only a few studies have compared multiple tests in the same study population. Alwani et al. (63) found that the Dex-CRH test and LNSC or MserC measurements achieved a high diagnostic accuracy in distinguishing between true CD and PCS. The results of the different tests were concordant in most patients, and combining the tests did not improve the diagnostic yield. The authors suggested using LNSC as the first choice, with each diagnostic center validating the diagnostic threshold. Other authors (64) recommended using the LDDST and MserC measurement at the start due to a low diagnostic performance of the Dex-CRH.

Tirabassi et al. (74) reported that the stimulation with human CRH and DDAVP tests showed an excellent diagnostic performance (sensitivity 96.6\%, specificity $100 \%$ for both). These tests showed a better agreement than those resulting from all other possible combinations of the other tests considered (UFC, 1-mg DST and serum cortisol circadian rhythm) in the same population of patients with CD or PCS. Using new interpretation criteria based on the simultaneous analysis of ACTH and cortisol $(69,73)$, the authors suggested using the human CRH or the DDAVP test, with no particular preference for either, and using both tests only in particular cases.

\section{Back to our patient}

The CRH test was performed after pre-treatment with $2 \mathrm{mg}$ dexamethasone for $48 \mathrm{~h}$ (cortisol $0.9 \mu \mathrm{g} / \mathrm{dL}$ to $1 \mu \mathrm{g} / \mathrm{dL}$ at $15 \mathrm{~min}$ ) followed by a DDAVP test (baseline cortisol: $19 \mu \mathrm{g} / \mathrm{dL}$ response: $21 \mu \mathrm{g} / \mathrm{dL}$; ACTH raised from 17 to $20 \mathrm{pg} / \mathrm{mL}$ ). The result of both tests was suggestive of PCS. Thus, the persistence of a mildly increased UFC level was judged to be due to inaccuracy of the assay method available.

The patient's follow-up, implementing lifestyle modifications for weight loss, showed a mild regression of the clinical signs of hypercortisolism, thereby reinforcing the diagnosis of PCS (in a case of real CS, they would have been expected to progress).

\section{Summary and a suggested approach}

Clinical situations involving HPA axis activation giving rise to a so-called PCS remain a major diagnostic challenge for endocrinologists.

Patients may present with obesity, DM, depression, and PCOS that are frequent in the general population. At diagnosis, the patients will often have already consulted several specialists (gynecologists, psychiatrists, and internists) and may have been given different treatments that could interfere with their laboratory test results or confer an additional risk for patients with an occult CS.

An accurate clinical examination is needed to identify any features that might help to discriminate cases of CS, but such signs might not be apparent in mild hypercortisolism, making its diagnosis more difficult.

An accurate treatment of any condition that may lead to a suspected PCS is important because it can reverse the related hormone abnormalities. We encourage physicians to consider CS particularly if the patient has more than one feature of the disorder or a poor control of the single situation despite maximal therapy.

The choice of the optimal screening test in a highrisk population relies on an expert understanding of the diagnostic performance of the various tests in different clinical settings. Although LC-MS/MS is probably the most accurate method for assessing UFC levels, have not achieved widespread use in routine clinical practice, and steroid cross-reactivity remains an issue when immunoassays are used to measure serum and urinary cortisol levels. LNSC needs to be further validated for use in this setting, demonstrating its accuracy in the differential diagnosis of PCS and CS.

Regarding the Dex-CRH test and/or the easier and less expensive DDAVP test, there is still debate on the optimal cut-off values for each of these tests in different clinical settings (obesity, MDD, and alcoholism), and none of them has become the gold standard for differentiating CS from PCS.

When a diagnosis is unreliable, we suggest treating the associated conditions and adopting a close follow-up, because the hypercortisolism associated with CS may progress, and the condition might consequently be diagnosed at a later date.

\section{Declaration of interest}

The authors declare that there is no conflict of interest that could be perceived as prejudicing the impartiality of this review.

This work is licensed under a Creative Commons Attribution-NonCommercial 4.0 International License. ded from Bioscientifica.com at 04/26/2023 06:56:14AM via free access 


\section{Funding}

This work did not receive any specific grant from any funding agency in the public, commercial or not-for-profit sector.

\section{Author contribution statement}

All authors contributed to the writing of the manuscript after a thorough literature search, dividing the work according to each single item treated, discussing the clinical case, and providing a critical feedback on the manuscript. Prof Scaroni, Prof Colao, and Prof Pivonello particularly conceived the original idea and contributed to the final version of the manuscript.

\section{References}

1 Tsigos C \& Chrousos GP. Hypothalamic-pituitary-adrenal axis, neuroendocrine factors and stress. Journal of Psychosomatic Research 200253 865-871. (https://doi.org/10.1016/s0022-3999(02)00429-4)

2 Newell-Price J, Trainer P, Besser M \& Grossman A. The diagnosis and differential diagnosis of Cushing's syndrome and pseudo-Cushing's states. Endocrine Reviews 199819 647-672. (https://doi.org/10.1210/ edrv.19.5.0346)

3 Nieman LK, Biller BM, Findling JW, Newell-Price J, Savage MO, Stewart PM \& Montori VM. The diagnosis of Cushing's syndrome: an Endocrine Society Clinical Practice Guideline. Journal of Clinical Endocrinology and Metabolism 200893 1526-1540. (https://doi. org/10.1210/jc.2008-0125)

4 Azziz R, Woods KS, Reyna R, Key TJ, Knochenhauer ES \& Yildis BO. The prevalence and features of the polycystic ovary syndrome in an unselected population. Journal of Clinical Endocrinology and Metabolism 200489 2745-2749. (https://doi.org/10.1210/jc.2003032046)

5 Arnardottir S \& Sigurjonsdottir HA. The incidence and prevalence of Cushing's disease may be higher than previously thought: results from a retrospective study in Iceland 1955 through 2009. Clinical Endocrinology 201174 792-793. (https://doi.org/10.1111/j.13652265.2010.03961.x)

6 Ceccato F \& Boscaro M. Cushing's syndrome: screening and diagnosis. High Blood Pressure and Cardiovascular Prevention 201623 209-215. (https://doi.org/10.1007/s40292-016-0153-4)

7 Antonelli G, Ceccato F, Artusi C, Marinova M \& Plebani M. Salivary cortisol and cortisone by LC-MS/MS: validation, reference intervals and diagnostic accuracy in Cushing's syndrome. Clinica Chimica Acta: International Journal of Clinical Chemistry $2015451247-251$. (https://doi.org/10.1016/j.cca.2015.10.004)

8 Papanicolaou DA, Mullen N, Kyrou I \& Nieman LK. Nighttime salivary cortisol: a useful test for the diagnosis of Cushing's syndrome. Journal of Clinical Endocrinology and Metabolism 200287 4515-4521. (https://doi.org/10.1210/jc.2002-020534)

9 Handelsman DJ \& Wartofsky L. Requirement for mass spectrometry sex steroid assays in the Journal of Clinical Endocrinology and Metabolism. Journal of Clinical Endocrinology and Metabolism 201398 3971-3973. (https://doi.org/10.1210/jc.2013-3375)

10 Hawley Hawley JM, Owen LJ, Debono M, Newel-Price J \& Keevil BG. Development of a rapid liquid chromatography tandem mass spectrometry method for the quantitation of serum dexamethasone and its clinical verification. Annals of Clinical Biochemistry 201855 665-672. (https://doi.org/10.1177/0004563218766566)

11 Vastbinder M, Kuindersma M, Mulder AH, Schuijt MP \& Mudde AH. The influence of oral contraceptives on overnight $1 \mathrm{mg}$ dexamethasone suppression test. Netherlands Journal of Medicine 2016 74 158-161.

12 Macut D, Božić Antić I, Nestorov J, Topalović V, Bjekić Macut J, Panidis D, Kastratović Kotlica B, Papadakis E, Matić G \& Vojnović
Milutinović D. The influence of combined oral contraceptives containing drospirenone on hypothalamic-pituitary-adrenocortical axis activity and glucocorticoid receptor expression and function in women with polycystic ovary syndrome. Hormones 201514 109-117. (https://doi.org/10.14310/horm.2002.1526)

13 Valassi E, Swearingen B, Lee H, Nachtigall LB, Donoho DA, Klibanski A \& Biller BM. Concomitant medication use can confound interpretation of the combined dexamethasone-corticotropin releasing hormone test in Cushing's syndrome. Journal of Clinical Endocrinology and Metabolism 200994 4851-4859. (https://doi. org/10.1210/jc.2009-1500)

14 Herbert J. Cortisol and depression: three questions for psychiatry. Psychological Medicine 201343 449-469. (https://doi.org/10.1017/ S0033291712000955)

15 Halbreich U, Asnis GM, Zumoff B, Nathan RS \& Shindledecker R. The effect of age and sex on cortisol secretion depressives and normals. Psychiatry Research 198413 221-229. (https://doi.org/10.1016/01651781(84)90037-4)

16 Young EA, Carlson NE \& Brown MB. Twenty-four hour ACTH and cortisol pulsatility in depressed women. Neuropsychopharmacology 200125 267-276. (https://doi.org/10.1016/S0893-133X(00)00236-0)

17 Deuschle M, Schweiger U, Weber B, Gotthardt U, Korner A, Schmider J, Standhardt H, Lammers CH \& Heuser I. Diurnal activity and pulsatility of the hypothalamus-pituitary-adrenal system in male depressed patients and healthy controls. Journal of Clinical Endocrinology and Metabolism 199782 234-238. (https://doi. org/10.1210/jcem.82.1.3689)

18 Portella MJ, Harmer CJ, Flint J, Cowen P \& Goodwin GM. Enhanced early morning salivary cortisol in neuroticism. American Journal of Psychiatry 2005162 807-809. (https://doi.org/10.1176/appi. ajp.162.4.807)

19 Keller J, Flores B, Gomez RG, Sovason HB, Kenna H, Williams GH \& Schatzberg AF. Cortisol circadian rhythm alterations in psychotic major depression. Biological Psychiatry 200660 275-281. (https://doi. org/10.1016/j.biopsych.2005.10.014)

20 Carroll BJ, Martin FI \& Davies B. Resistance to suppression by dexamethasone of plasma 11-O.H.C.S. levels in severe depressive illness. British Medical Journal 19683 285-287. (https://doi. org/10.1136/bmj.3.5613.285)

21 Carroll BJ. Use of the dexamethasone suppression test in depression. Journal of Clinical Psychiatry 198243 44-50.

22 Anacker C, Zunszain PA, Carvalho LA \& Pariante CM. The glucocorticoid receptor: pivot of depression and of antidepressant treatment? Psychoneuroendocrinology 201136 415-425. (https://doi. org/10.1016/j.psyneuen.2010.03.007)

23 Sachar EJ, Hellman L, Roffwarg HP, Halpern FS, Fukushima DK \& Gallagher TF. Disrupted 24-hour patterns of cortisol secretion in psychotic depression. Archives of General Psychiatry 197328 19-24. (https://doi.org/10.1001/archpsyc.1973.01750310011002)

24 Mortola JF, Liu JH, Gillin JC, Rasmussen DD \& Yen SS. Pulsatile rhythms of adrenocorticotropin (ACTH) and cortisol in women with endogenous depression: evidence of increased ACTH pulse frequency. Journal of Clinical Endocrinology and Metabolism 198765 962-968. (https://doi.org/10.1210/jcem-65-5-962)

25 Römer B, Lewicka S, Kopf D, Lederbogen F, Hamann B, Gilles M, Schilling C, Onken V, Frankhauser P \& Deuschle M. Cortisol metabolism in depressed patients and healthy controls. Neuroendocrinology 200990 301-306. (https://doi. org/10.1159/000235904)

26 Gragnoli C. Depression and type 2 diabetes: cortisol pathway implication and investigational needs. Journal of Cellular Physiology 2012227 2318-2322. (https://doi.org/10.1002/jcp.23012)

27 Penninx BW, Beekman AT, Honig A, Deeg DJ, Schoevers RA, van Eijk JT \& van Tilburg W. Depression and cardiac mortality: results from a community-based longitudinal study. Archives of General Psychiatry 200158 221-227. (https://doi.org/10.1001/archpsyc.58.3.221)

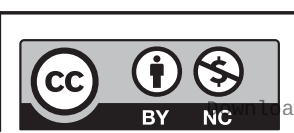

This work is licensed under a Creative Commons Attribution-NonCommercial 4.0 International License. ded from Bioscientifica.com at 04/26/2023 06:56:14AM 
28 Coryell W, Fiedorowicz J, Zimmerman M \& Young E. HPA axis hyperactivity and mortality in psychotic depressive disorder: preliminary findings. Psychoneuroendocrinology 200833 654-658. (https://doi.org/10.1016/j.psyneuen.2008.02.005)

29 Brzana J, Yedinak CG, Hameed N, Plesiu A, McCartney S \& Fleseriu M. Polycystic ovarian syndrome and Cushing's syndrome: a persistent diagnostic quandary. European Journal of Obstetrics, Gynecology, and Reproductive Biology 2014175 145-148. (https://doi. org/10.1016/j.ejogrb.2013.12.038)

30 Kaltsas GA, Korbonits M, Isidori AM, Webb JA, Trainer PJ, Monson JP, Besser GM \& Grossman AB. How common are polycystic ovaries and the polycystic ovarian syndrome in women with Cushing's syndrome? Clinical Endocrinology 200053 493-500. (https://doi. org/10.1046/j.1365-2265.2000.01117.x)

31 Penezić Z, Zarković M, Vujović S, Cirić J, Beleslin B, Ivović M, Pokrajac A \& Drezgić M. Gonadotropin pulsatility in Cushing's syndrome compared with polycystic ovary syndrome. Gynecological Endocrinology 200520 150-154. (https://doi. org/10.1080/09513590400027190)

32 Pall ME, Lao MC, Patel SS, Lee ML, Ghoids DE, Chandler DW \& Friedman TC. Testosterone and bioavailable testosterone help to distinguish between mild Cushing's syndrome and polycystic ovarian syndrome. Hormone and Metabolic Research 200840 813-818. (https://doi.org/10.1055/s-0028-1087186)

33 Putignani P, Bertolini M, Losa M \& Cavagnini F. Screening for Cushing's syndrome in obese women with and without polycystic ovary syndrome. Journal of Endocrinological Investigation 200326 539-544. (https://doi.org/10.1007/BF03345217)

34 Invitti C, Pecori Giraldi F, Dubini A, De Martin M \& Cavagnini F. Increased urinary free cortisol and decreased serum corticosteroidbinding globulin in polycystic ovary syndrome. Acta Endocrinologica 1991125 28-32. (https://doi.org/10.1530/acta.0.1250028)

35 Terzolo M, Reimondo G, Chiodini I, Castello R, Giordano R, Ciccarelli E, Limone P, Crivellaro C, Martinelli I, Montini M, et al. Screening of Cushing's syndrome in outpatients with type 2 diabetes: results of a prospective multicentric study in Italy. Journal of Clinical Endocrinology and Metabolism 201297 3467-3475. (https://doi. org/10.1210/jc.2012-1323)

36 Catargi B, Rigalleau V, Poussin A, Ronci-Chaix N, Bex V, Vergnot V, Gin H, Roger P \& Tabarin A. Occult Cushing's syndrome in type-2 diabetes. Journal of Clinical Endocrinology and Metabolism $2003 \mathbf{8 8}$ 5808-5813. (https://doi.org/10.1210/jc.2003-030254)

37 Incollingo Rodriguez AC, Epel ES, White ML, Standen EC, Seckl JR \& Tomiyama AJ. Hypothtalamic-pituitary-adrenal axis dysregulation and cortisol activity in obesity; a systematic review. Psychoneuroendocrinology 201562 301-318. (https://doi. org/10.1016/j.psyneuen.2015.08.014)

38 Björntorp P \& Rosmond R. Obesity and cortisol. Nutrition 200016 924-936. (https://doi.org/10.1016/s0899-9007(00)00422-6)

39 Rask E, Walker BR, Söderberg S, Livingstone DE, Eliasson M, Johnson O, Andrew R \& Olsson T. Tissue-specific changes in peripheral cortisol metabolism in obese women: increased adipose 11beta-hydroxysteroid dehydrogenase type 1 activity. Journal of Clinical Endocrinology and Metabolism 200287 3330-3336. (https:// doi.org/10.1210/jcem.87.7.8661)

40 Vicennati V \& Pasquali R. Abnormalities of the hypothalamicpituitary-adrenal axis in non depressed women with abdominal obesity and relations with insulin resistance: evidence for a central and peripheral alteration. Journal of Clinical Endocrinology and Metabolism 200085 4093-4098. (https://doi.org/10.1210/jcem.85.11.6946)

41 Mårin P, Darin N, Amemiya T, Andersson B, Jern S \& Björntorp P. Cortisol secretion in relation to body fat distribution in obese premenopausal women. Metabolism: Clinical and Experimental 1992 41 882-886. (https://doi.org/10.1016/0026-0495(92)90171-6)

42 Pasquali R, Cantobelli S, Casimirri F, Capelli M, Bortoluzzi L, Flamia R, Labate AM \& Barbara L. The hypothalamic-pituitary adrenal axis in obese women with different patterns of body fat distribution. Journal of Clinical Endocrinology and Metabolism 199377 341-346. (https://doi.org/10.1210/jcem.77.2.8393881)

43 Rosmond R, Dallman MF \& Björntorp P. Stress-related cortisol secretion in men: relationships with abdominal obesity and endocrine metabolic and hemodynamic abnormalities. Journal of Clinical Endocrinology and Metabolism 199883 1853-1859. (https:// doi.org/10.1210/jcem.83.6.4843)

44 Pasquali R, Ambrosi B, Armanini D, Cavagnini F, Degli Uberti ED, Del Rio G, de Pergola G, Maccario M, Mantero F, Marugo M, et al. Cortisol and ACTH response to oral dexamethasone in obesity and effects on sex, body fat distribution and dexamethasone concentrations; a dose-response study. Journal of Clinical Endocrinology and Metabolism 200287 166-175. (https://doi. org/10.1210/jcem.87.1.8158)

45 Abraham SB, Rubino D, Sinaii N, Ramsey S \& Nieman LK. Cortisol, obesity and the metabolic syndrome: a cross-sectional study of obese subjects and review of the literature. Obesity 201321 E105-E117. (https://doi.org/10.1002/oby.20083)

46 Morton NM. Obesity and corticosteroids: 11beta-hydroxysteroid type 1 as a cause and therapeutic target in metabolic disease. Molecular and Cellular Endocrinology 2010316 154-164. (https://doi. org/10.1016/j.mce.2009.09.024)

47 Gathercole LL \&. Stewart PM. Targeting the pre-receptor metabolism of cortisol as a novel therapy in obesity and diabetes. Journal of Steroid Biochemistry and Molecular Biology 2010122 21-27. (https:// doi.org/10.1016/j.jsbmb.2010.03.060)

48 Mariniello B, Ronconi V, Rilli S, Bernante P, Boscaro M, Mantero F \& Giachetti G. Adipose tissue 11 beta-hydroxysteroid dehydrogenase type 1 expression in obesity and Cushing's syndrome. European Journal of Endocrinology 2006155 435-441. (https://doi.org/10.1530/ eje.1.02228)

49 Dammann C, Stapelfeld C \& Maser E. Expression and activity of the cortisol-activating enzyme $11 \beta$-hydroxysteroid dehydrogenase type 1 is tissue and species-specific. Chemico-Biological Interactions 2019303 57-61. (https://doi.org/10.1016/j.cbi.2019.02.018)

50 Zhao L, Pan Y, Peng K, Wang Z, Li J, Li D, Tong C, Wang Y \& Liang G. Inhibition of $11 \beta$-HSD1 by LG13 improves glucose metabolism in type 2 diabetic mice. Journal of Molecular Endocrinology 201555 119-131. (https://doi.org/10.1530/JME-14-0268)

51 Rees LH, Besser GM, Jeffcoate WJ, Goldie DJ \& Marks V. Alcoholinduced pseudo-Cushing's syndrome. Lancet 19771 726-728. (https://doi.org/10.1016/s0140-6736(77)92169-9)

52 Jimenez VA, Helms CM, Cornea A, Meshul CK \& Grant KA. An ultrastructural analysis of the effects of ethanol self-administration on the hypothalamic paraventricular nucleus in rhesus macaques. Frontiers in Cellular Neuroscience 20159 260. (https://doi.org/10.3389/ fncel.2015.00260)

53 Besemer F, Pereira AM \& Smit JWA. Alcohol-induced Cushing syndrome. Hypercortisolism caused by alcohol abuse. Netherlands Journal of Medicine 201169 318-323.

54 Coiro V, Volpi R, Galli P, Manfredi G, Magotti MG, SaccaniJotti G \& Chiodera P. Serum total prostate-specific antigen assay in women with Cushing's disease or alcohol-dependent pseudoCushing's state. Hormone Research 200461 148-152. (https://doi. org/10.1159/000075671)

55 Frias J, Rodriguez R, Torres JM, Ruiz E \& Ortega E. Effects of acute alcohol intoxication on pituitary-gonadal axis hormones, pituitaryadrenal axis hormones, beta-endorphin and prolactin in human adolescents of both sexes. Life Sciences 200067 1081-1086. (https:// doi.org/10.1016/s0024-3205(00)00702-5)

56 Stalder T, Kirschbaum C, Heinze K, Steudte S, Foley P, Tietze A \& Dettenbrn L. Use of hair cortisol analysis to detect hypercortisolism during active drinking phases in alcohol-dependent individuals. Biological Psychology 201085 357-360. (https://doi.org/10.1016/j. biopsycho.2010.08.005)

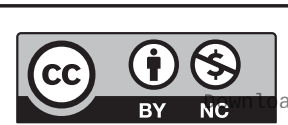

This work is licensed under a Creative Commons Attribution-NonCommercial 4.0 International License. ded from Bioscientifica com at 04/26/2023 06:56:14AM 
57 Beresford TP, Arciniegas DB, Alfers J, Clapp L, Martin B, Beresford HF Du Y, Liu D, Shen D, Davatzikos C, et al. Hypercortisolism in alcohol dependence and its relation to hippocampal volume loss. Journal of Studies on Alcohol $2006 \mathbf{6 7}$ 861-867. (https://doi.org/10.15288/ jsa.2006.67.861)

58 Aron DC, Tyrrell JB, Fitzgerald PA, Findling JW \& Forsham PH. Cushing's syndrome: problems in diagnosis. Medicine 198160 25-35. (https://doi.org/10.1097/00005792-198101000-00003)

59 Mayer L, Walsh BT, Pierson Jr RN, Heymsfield SB, Gallagher D, Wang J, Parides MK, Leibel RL, Warren MP, Killory E, et al. Body fat redistribution after weight gain in women with anorexia nervosa. American Journal of Clinical Nutrition 200581 1286-1291. (https:// doi.org/10.1093/ajcn/81.6.1286)

60 Connan F, Lightman SL, Landau S, Wheeler M, Treasure J \& Campbell IC. An investigation of hypothalamic-pituitary-adrenal axis hyperactivity in anorexia nervosa: the role of CRH and AVP. Journal of Psychiatric Research 200741 131-143. (https://doi. org/10.1016/j.jpsychires.2005.12.005)

61 dos Santos E, dos Santos JE, Ribeiro RP, Rosa E Silva AC, Moreira AC \& Silva de Sá MF. Absence of circadian salivary cortisol rhythm in women with anorexia nervosa. Journal of Pediatric and Adolescent Gynecology 200720 13-18. (https://doi.org/10.1016/j. jpag.2006.10.011)

62 Papanicolaou DA, Yanovski JA, Cutler Jr GB, Chrousos GP \& Nieman LK. A single midnight serum cortisol measurement distinguishes Cushing's syndrome from pseudo-Cushing states. Journal of Clinical Endocrinology and Metabolism 199883 1163-1167. (https://doi.org/10.1210/jcem.83.4.4733)

63 Alwani RA, Schmit Jongbloed LW, de Jong FH, van der Lely AJ, de Herder WW \& Feelders RA. Differentiating between Cushing's disease and pseudo-Cushing's syndrome: comparison of four tests. European Journal of Endocrinology 2014170 477-486. (https://doi.org/10.1530/ EJE-13-0702)

64 Gatta B, Chabre O, Cortet C, Martinie M, Corcuff JB, Roger P $\&$ Tabarin A. Reevaluation of the combined dexamethasone suppression-corticotropin-releasing hormone test for differentiation of mild Cushing's disease from pseudo-Cushing's syndrome. Journal of Clinical Endocrinology and Metabolism 200792 4290-4293. (https:// doi.org/10.1210/jc.2006-2829)

65 Yanovski JA, Cutler Jr GB, Chrousos GP \& Nieman LK. Corticotropinreleasing hormone stimulation following low-dose dexamethasone administration. A new test to distinguish Cushing's syndrome from pseudo-Cushing's states. JAMA 1993269 2232-2238.

66 Martin NM, Dhillo WS, Banerjee A, Abdulali A, Jayasena CN, Donaldson M, Todd JF \& Meeran K. Comparison of the dexamethasone-suppressed corticotropin-releasing hormone test and low-dose dexamethasone suppression test in the diagnosis of Cushing's syndrome. Journal of Clinical Endocrinology and Metabolism 200691 2582-2586. (https://doi.org/10.1210/jc.2005-2143)

67 Erickson D, Natt N, Nippoldt T, Young Jr WF, Carpenter PC, Petterson T \& Christianson T. Dexamethasone-suppressed corticotropin-releasing hormone stimulation test for diagnosis of mild hypercortisolism. Journal of Clinical Endocrinology and Metabolism 200792 2972-2976. (https://doi.org/10.1210/jc.20062662)

68 Arnaldi G, Angeli A, Atkinson AB, Bertagna X, Cavagnini F, Chrousos GP, Fava GA, Findling JW, Gaillard RC, Grossman AB, et al. Diagnosis and complications of Cushing's syndrome: a consensus statement. Journal of Clinical Endocrinology and Metabolism $2003 \mathbf{8 8}$ 5593-5602. (https://doi.org/10.1210/jc.2003-030871)

69 Arnaldi G, Tirabassi G, Papa R, Furlani G, Trementino L, Cardinaletti M, Faloia E \& Boscaro M. Human corticotropin releasing hormone test performance in the differential diagnosis between Cushing's disease and pseudo-Cushing state is enhanced by combined ACTH and cortisol analysis. European Journal of Endocrinology 2009160 891-898. (https://doi.org/10.1530/EJE-090125)

70 Pecori Giraldi F, Pivonello R, Ambrogio AG, De Martino MC, De Martin M, Scacchi M, Colao A, Toja PM, Lombardi G \& Cavagnini F. The dexamethasone-suppressed corticotropin-releasing hormone stimulation test and the desmopressin test to distinguish Cushing's syndrome from pseudo-Cushing's states. Clinical Endocrinology 2007 66 251-257. (https://doi.org/10.1111/j.1365-2265.2006.02717.x)

71 Moro M, Putignano P, Losa M, Invitti C, Maraschini C \& Cavagnini F. The desmopressin test in the differential diagnosis between Cushing's disease and pseudo-Cushing states. Journal of Clinical Endocrinology and Metabolism 200085 3569-3574. (https://doi. org/10.1210/jcem.85.10.6862)

72 Rollin GAF, Costenaro F, Gerchman F, Rodrigues TC \& Czepielewski MA. Evaluation of the DDAVP test in the diagnosis of Cushing's disease. Clinical Endocrinology 201582 793-800. (https:// doi.org/10.1111/cen.12661)

73 Tirabassi G, Faloia E, Papa R, Furlani G, Boscaro M \& Arnaldi G. Use of the desmopressin test in the differential diagnosis of pseudoCushing state from Cushing's disease. Journal of Clinical Endocrinology and Metabolism 201095 1115-1122. (https://doi.org/10.1210/ jc.2009-1146)

74 Tirabassi G, Papa R, Faloia E, Boscaro M \& Arnaldi G. Corticotrophinreleasing hormone and desmopressin tests in the differential diagnosis between Cushing's disease and pseudo-Cushing state: a comparative study. Clinical Endocrinology 201175 666-672. (https:// doi.org/10.1111/j.1365-2265.2011.04096.x)

Received in final form 29 November 2019

Accepted 16 December 2019

Accepted Manuscript published online 17 December 2019 https://ec.bioscientifica.com https://doi.org/10.1530/EC-19-0435 (c) 2020 The authors Published by Bioscientifica Ltd

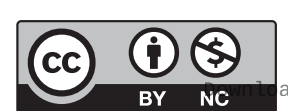

This work is licensed under a Creative Commons Attribution-NonCommercial 4.0 International License. ded from Bioscientifica.com at 04/26/2023 06:56:14AM 